\title{
Direct Chromatographic Resolution and Isolation of the Four Stereoisomers of meta-Hydroxyphenylpropanolamine
}

\author{
MARCIAN E. VAN DORT* \\ Division of Nuclear Medicine, Department of Internal Medicine, University of Michigan Medical School, \\ Ann Arbor, Michigan
}

\begin{abstract}
Methods for the direct chiral chromatographic separation of the four stereoisomers of meta-hydroxyphenylpropanolamine (MHPA) on an analytical and preparative scale are described. Separations were carried out on a Crownpak CR (+) chiral column with $113 \mathrm{mM}$ aqueous perchloric acid as the mobile phase. Baseline resolution of the more retained $(+)$-stereoisomers (1S configuration) and partial resolution of the less retained (-)-stereoisomers (1R configuration) were obtained under these chromatographic conditions. Removal of the bulk of the (1R,2S)-stereoisomer (metaraminol) from the initial crude mixture by fractional crystallization as the (+)-bitartarate salt substantially improved the peak resolution factors (Rs) of the remaining three stereoisomers. Semipreparative chromatographic resolution of the latter isomeric mixture provided milligram quantities of each stereoisomer in $>97 \%$ enantiomeric excess. Subsequent recrystallization of their bitartarate or fumarate salts gave enantiomeric purities $>99 \%$. Chirality 11:684-688, 1999. (c) 1999 Wiley-Liss, Inc.
\end{abstract}

KEY WORDS: chiral resolution; cardiac imaging; metaraminol; positron emission tomography; sympathomimetic amines; preparative chromatography

Radiolabeled biogenic amines have achieved widespread utility as neuronal markers for monoaminergic neurons. In recent years, a variety of derivatives labeled with either carbon-11 or fluorine-18 have been developed as positron emission tomography (PET) radiotracers for in vivo studies of the peripheral noradrenergic neuronal system. ${ }^{1-5}$ Studies in our laboratory have focused on the synthetic norepinephrine analog metaraminol (1a; Fig. 1), a clinically used vasopressor. ${ }^{6}$ Metaraminol was shown to accumulate in sympathetic nerve endings upon systemic administration. ${ }^{6,7}$ We subsequently synthesized carbon-11labeled N-methylmetaraminol ([C-11] metahydroxyephedrine, [C-11]HED) by direct N-methylation of commercially available metaraminol with $[\mathrm{C}-11] \mathrm{CH}_{3} \mathrm{I}$ for use as a PET radiotracer for mapping sympathetic neurons. ${ }^{8}$ PET studies with [C-11] HED have allowed noninvasive assessment of the integrity of the human cardiac sympathetic nervous system in the normal and transplanted heart, as well as in disease states such as acute myocardial infarction and diabetic neuropathy. ${ }^{9-12}$

Metaraminol [(-)-(1R,2S)-1-( $m$-hydroxyphenyl)-2-amino1-propanol], is one of four possible stereoisomers (two racemic diastereomers: erythro and threo, respectively) of meta-hydroxyphenylpropanolamine (MHPA; Fig. 1). As part of a program aimed at evaluating the neuronal mapping potential of the remaining three stereoisomers of [C-11]HED, we required convenient access to enantiomerically pure, milligram quantities of their corresponding MHPA stereoisomers for carbon-11 labeling. Although a (C) 1999 Wiley-Liss, Inc. two-step synthetic route for the conversion of metaraminol to the $(1 \mathrm{~S}, 2 \mathrm{~S})$-stereoisomer (1d) has been reported in the literature, ${ }^{13}$ the latter and remaining two stereoisomers $(\mathbf{1 b}, \mathbf{1 c})$ of MHPA are currently unavailable from commercial sources. In this report, we describe a chiral chromatographic method for the direct optical resolution of the four individual MHPA stereoisomers and their corresponding physical and spectral properties.

\section{MATERIALS AND METHODS Chemicals}

Dowex $^{\circledR} 50 \mathrm{~W}-\mathrm{X} 8$ cation-exchange resin (400 mesh, strongly acidic) and all chemical reagents were obtained from Aldrich Chemical Co. (Milwaukee, WI). Absolute ethanol was obtained from Midwest Grain Products of Illinois (Pekin, IL). Metaraminol (1a), was purchased from Sigma Chemical Co. (St Louis, MO). An analytical sample of ( \pm )-threo-MHPA (1c, 1d) as the naphthalene hemisulfonate salt was kindly provided by Sterling Winthrop Research Institute (Rensselaer, NY).

\footnotetext{
Contract grant sponsor: National Institutes of Health; Contract grant numbers: HL27555, HL47543.

${ }^{\star}$ Correspondence to: Marcian E. Van Dort, Ph.D., Division of Nuclear Medicine, 3480 Kresge III Building, University of Michigan Medical School, Ann Arbor, MI 48109-0552. E-mail: mvandort@umich.edu Received for publication 22 February 1999; Accepted 5 May 1999
} 


\section{Erythro series}

\section{Threo series}<smiles>C[C@H](N)[C@H](O)c1cccc(O)c1</smiles>

$1 S, 2 R$

(1b)<smiles>C[C@H](N)[C@H](O)c1cccc(O)c1</smiles>

$1 R, 2 R$

(1c) (metaraminol, 1a)

Fig. 1. Stereoisomers of meta-hydroxyphenylpropanolamine (MHPA).<smiles>C[C@H](N)[C@H](O)c1cccc(O)c1</smiles>

1S, $2 S$

(1d)

\section{General Instrumentation}

${ }^{1} \mathrm{H}$ NMR spectra were obtained in $\mathrm{CD}_{3} \mathrm{OD}$ on a Bruker WM-360 (360 MHz) instrument with tetramethylsilane (TMS) as internal standard. Mass spectra were obtained on a Finnigan 4021 GCMS/DS (low resolution) or a UG70250-S (high resolution) instrument. Optical rotations were measured at $589 \mathrm{~nm}$ in a $1 \mathrm{ml}$ quartz microcell of $1 \mathrm{dm}$ optical pathlength using a Perkin-Elmer (Norwalk, CT) 241 polarimeter and $c$ is expressed in $\mathrm{g} / 100 \mathrm{~mL}$. Melting points were determined in open capillary tubes using a Thomas Hoover melting point apparatus and are uncorrected.

\section{Chromatography}

The HPLC system consisted of a Beckman (Palo Alto, CA) Model 421 controller, Model 112 pump, a Rheodyne 7161 injector equipped with a $1.0 \mathrm{ml}$ sample loop, and an Applied Biosystems (Foster City, CA) Model 757 UV variable wavelength absorbance detector interfaced with a Waters (Rochester, MN) Model 740 electronic integrator. Mobile phase solutions were prepared using distilled deionized water from a Milli-Q system (Millipore, Bedford, MA) and filtered through a $0.45-\mu \mathrm{m}$ filter prior to use. All chromatographic procedures were conducted at ambient temperature.

Analytical chromatography was carried out on a Crownpak CR (+) column $(150 \times 4$ mm i.d., $5 \mu \mathrm{m}$; Daicel Chemical Industries, Tokyo, Japan) using $113 \mathrm{mM}$ aqueous perchlo- ric acid (pH 1) as mobile phase at a flow rate of $0.5 \mathrm{ml} / \mathrm{min}$ with UV detection at $254 \mathrm{~nm}$. Samples for injection were dissolved in the mobile phase and filtered through a 0.45 $\mu \mathrm{m}$ filter prior to use. Analytical runs with either the authentic standards or the crude mixture of stereoisomers were conducted using $10-25-\mu 1$ injections from a $1 \mathrm{mg} / \mathrm{ml}$ stock solution.

Preparative chromatography was conducted using a 150 $\times 10 \mathrm{~mm}$ i.d. Crownpak CR (+) column at a flow rate of 2 $\mathrm{ml} / \mathrm{min}$ with UV detection at $290 \mathrm{~nm}$. Separations were

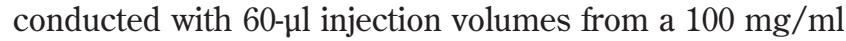
stock solution of Mixture B. For each run, approximately ten $1 \mathrm{ml}$ fractions were collected during elution of the first three components (1c, 1a, 1d) followed by five $2 \mathrm{ml}$ fractions during the elution of $\mathbf{1} \mathbf{b}$. Fractions were reinjected on the analytical system for confirmation of their optical purity. The limit of detection for each stereoisomer was approximately $0.1 \%$ (peak area) at a signal-to-noise ratio of 4 .

\section{Chromatographic Parameters}

The capacity factors $\left(\mathrm{k}^{\prime}\right)$ were calculated using the equation $\mathrm{k}^{\prime}=\left(\mathrm{t}_{\mathrm{R}}-\mathrm{t}_{0}\right) / \mathrm{t}_{0}$ where $\mathrm{t}_{\mathrm{R}}$ is the elution time and $\mathrm{t}_{0}$ is the elution time for an unretained sample. The $t_{0}$ for the analytical column was $3.6 \mathrm{~min}$ at a flow rate of $0.5 \mathrm{ml}$ per min as determined by injection of 1,3,5-tri-tert-butylbenzene as the unretained standard. Elution times are the average of triplicate determinations. Peak resolution (Rs) and separa- 
tion $(\alpha)$ factors were calculated for each critical pair (closest eluting pair of stereoisomers) as previously described. ${ }^{14}$

\section{Synthesis of MHPA Stereoisomers}

A mixture containing the four stereoisomers of MHPA was synthesized from propiophenone in $20 \%$ overall yield using published procedures. ${ }^{15,16}(+)-(1 \mathrm{~S}, 2 \mathrm{~S})-\mathrm{MHPA}$ (1d) was also synthesized from metaraminol by an alternate route, as previously described ${ }^{13}$ for use as an analytical standard. All compounds had satisfactory physical and spectral properties ( ${ }^{1} \mathrm{H}$ NMR, mass spectral data).

\section{Isolation of Metaraminol (1a) from MHPA Isomeric Mixture}

Two grams of the MHPA isomeric mixture (Mixture A) was treated with a solution of (+)-(2R,3R)-tartaric acid (1.7 $\mathrm{g}, 11.3 \mathrm{mmoles}$ ) in $25 \mathrm{ml}$ of hot $95 \% \mathrm{EtOH}$. The mixture was heated to boiling and filtered to remove a small quantity of an insoluble white residue. Crystallization commenced at ambient temperature after concentration of the mixture to a volume of approximately $20 \mathrm{ml}$. The mixture was stored at $-20^{\circ} \mathrm{C}$ overnight and filtered to provide $720 \mathrm{mg}$ of the (+)-bitartarate salt of metaraminol (1a) having a 95\% enantiomeric excess (ee) by chiral HPLC analysis. Concentration and cooling of the filtrate provided an additional 270 $\mathrm{mg}$ of $\mathbf{1 a}$ of approximately $92 \%$ ee. The combined products were recrystallized three times from $\mathrm{EtOH}$ to provide 1a with $>99 \%$ optical purity. Concentration of the original mother liquor (Mixture B) gave a brown gummy residue $(2.5 \mathrm{~g})$ which was dissolved in water $(10 \mathrm{ml})$ and converted to the free base by cation-exchange chromatography (see below) using approximately $15 \mathrm{~g}$ of resin.

\section{Isolation of Free Base Forms of Individual MHPA Stereoisomers by Cation-Exchange Chromatography}

Five grams of Dowex ${ }^{\circledR} 50 \mathrm{~W}-\mathrm{X} 8$ resin was rinsed with ethanol $(3 \times 10 \mathrm{ml})$ until the eluant was clear. The wet resin was introduced into a glass chromatography column $(2 \mathrm{~cm}$ i.d.) and eluted with deionized water $(3 \times 20 \mathrm{ml})$ until the $\mathrm{pH}$ of eluant was equal to that of pure deionized water $(\mathrm{pH}$ 5.5-6.0). The pooled HPLC eluant fractions containing the pure MHPA stereoisomer were then eluted through the resin column with a low positive air pressure (2-3 psi) and the resin was rinsed once more with deionized water until eluant $\mathrm{pH}$ range was between 5.5 and 6.0. Elution with 30 $\mathrm{ml}$ of $4 \mathrm{~N}$ ethanolic ammonia $\left(\mathrm{NH}_{4} \mathrm{OH}: \mathrm{EtOH} ; 35: 65\right)$ and concentration of the eluate under reduced pressure at $40^{\circ} \mathrm{C}$ afforded the stereoisomer as the free base. The latter were obtained as amorphous solids by successive trituration of the residue with absolute $\mathrm{EtOH}$ and dry ethyl ether.

(-)-(1R,2S)-1-(m-hydroxyphenyl)-2-amino-1-propanol (1a) Treatment of the free base with an equivalent portion of $(+)-(2 \mathrm{R}, 3 \mathrm{R})$-tartaric acid and recrystallization from EtOH provided the (+)-bitartarate salt: $\mathrm{mp} 175-177^{\circ} \mathrm{C}$ (dec) (lit. $\left.{ }^{17} 176-177^{\circ} \mathrm{C}\right) ;[\alpha]^{25}$ for $\mathrm{HCl}$ salt $=-21^{\circ}(c=0.1$, $\mathrm{H}_{2} \mathrm{O}$ ) $\left\{\right.$ lit. $\left.^{17}[\alpha]^{25}{ }_{\mathrm{D}}=-19.75^{\circ}\right\}$; ${ }^{1} \mathrm{H}$ NMR (free base in $\left.\mathrm{CD}_{3} \mathrm{OD}\right) \delta 7.15(\mathrm{t}, 1 \mathrm{H}), 6.81(\mathrm{~m}, 2 \mathrm{H}), 6.70(\mathrm{~d}, 1 \mathrm{H}), 4.37(\mathrm{~d}$, $1 \mathrm{H}, \mathrm{J}=5.62 \mathrm{~Hz}), 4.90(\mathrm{~s}, 4 \mathrm{H}), 3.00(\mathrm{dq}, 1 \mathrm{H}, \mathrm{J}=6.13 \mathrm{~Hz})$,

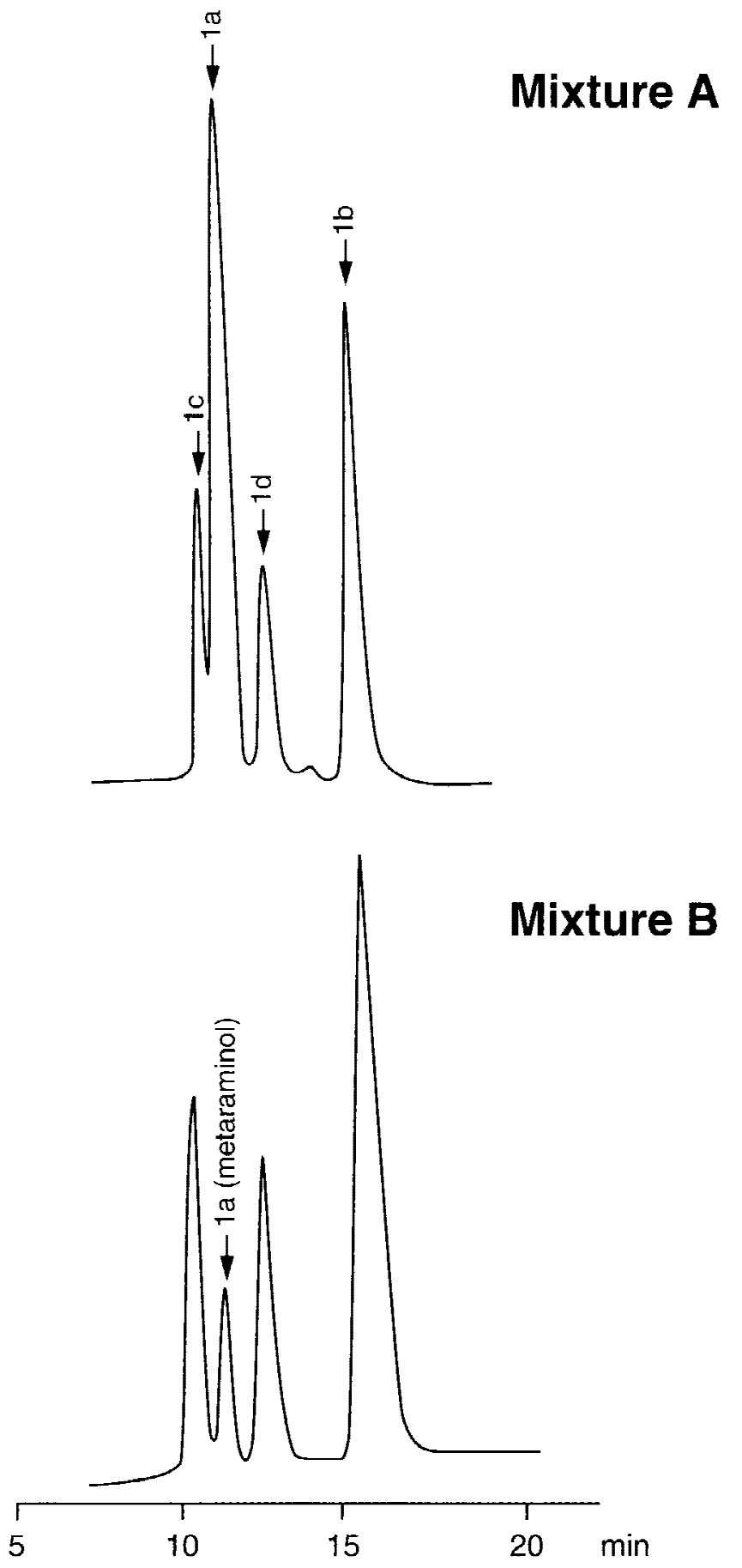

Fig. 2. Chromatograms showing relative enantiomeric composition of MHPA stereoisomers: in crude synthetic product mixture (Mixture A), in mother liquor (Mixture B) after selective removal of (-)-metaraminol (1a) by fractional crystallization. See text for experimental details.

$1.05(\mathrm{~d}, 3 \mathrm{H}, \mathrm{J}=6.46 \mathrm{~Hz})$; high resolution MS (DCI with $\left.\mathrm{NH}_{3}\right) \mathrm{m} / \mathrm{z} 168.1020\left(\mathrm{C}_{9} \mathrm{H}_{14} \mathrm{NO}_{2}\left[\mathrm{M}+\mathrm{H}^{+}\right]\right.$requires 168.1024).

(+)-(1S,2R)-1-(m-hydroxyphenyl)-2-amino-1-propanol (1b) The free base was treated with (-)-(2S,3S)-tartaric acid as described above and the (-)-bitartarate salt recrys- 
RESOLUTION OF MHPA

TABLE 1. Chromatographic parameters for MHPA stereoisomers in Mixture A

\begin{tabular}{|c|c|c|c|c|c|c|c|}
\hline Stereoisomer & 1c & & $1 \mathbf{a}$ & & 1d & & $1 b$ \\
\hline Capacity factor $\left(\mathrm{k}^{\prime}\right)$ & 2.06 & & 2.22 & & 2.61 & & 3.32 \\
\hline Separation factor $(\alpha)$ & & 1.08 & & 1.17 & & 1.27 & \\
\hline Resolution (Rs) & & $\begin{array}{c}(1 \mathrm{a}, \mathbf{1}) \\
0.92\end{array}$ & & $\begin{array}{l}\text { (1d, 1a) } \\
1.57\end{array}$ & & $\begin{array}{c}(10,10) \\
2.35\end{array}$ & \\
\hline (Critical pair) & & $(1 \mathrm{a}, 1 \mathrm{c})$ & & $(1 \mathrm{~d}, 1 \mathrm{a})$ & & $(1 \mathrm{~b}, 1 \mathrm{~d})$ & \\
\hline
\end{tabular}

tallized from EtOH to provide an analytical sample: $\mathrm{mp}$ $175-177^{\circ} \mathrm{C}$ (dec) (lit. $\left.{ }^{18} 179-181^{\circ} \mathrm{C}\right) ;[\alpha]^{25}{ }_{\mathrm{D}}=+5^{\circ}(c=0.1$, $\left.\mathrm{H}_{2} \mathrm{O}\right)\left\{\right.$ lit. $\left.{ }^{18}[\alpha]^{25}{ }_{\mathrm{D}}=+4.4^{\circ}\left(c=1, \mathrm{H}_{2} \mathrm{O}\right)\right\}$. The ${ }^{1} \mathrm{H}$ NMR and mass spectral data corresponded with that reported for the $(1 \mathrm{R}, 2 \mathrm{~S})$ isomer above.

(-)-(1R,2R)-1-(m-hydroxyphenyl)-2-amino-1-propanol (1c) The fumarate salt was prepared from the free base and recrystallized from $\mathrm{CH}_{3} \mathrm{OH}$ :EtOAc (1:3) to provide an analytical sample: $\mathrm{mp} 210-212^{\circ} \mathrm{C}$ (dec) (lit. ${ }^{13} 208.2-$ $\left.209.7^{\circ} \mathrm{C}\right) ;[\alpha]^{25}{ }_{\mathrm{D}}=-32^{\circ}\left(c=0.1, \mathrm{H}_{2} \mathrm{O}\right)\left\{\right.$ lit. $^{13}[\alpha]^{25}{ }_{\mathrm{D}}=-28^{\circ}$ $\left.\left(c=2, \mathrm{H}_{2} \mathrm{O}\right)\right\} .{ }^{1} \mathrm{H}$ NMR (free base in $\left.\mathrm{CD}_{3} \mathrm{OD}\right) \delta 7.14(\mathrm{t}, 1 \mathrm{H})$, $6.78(\mathrm{~m}, 2 \mathrm{H}), 6.69(\mathrm{~d}, 1 \mathrm{H}), 4.16(\mathrm{~d}, 1 \mathrm{H}, \mathrm{J}=7.54 \mathrm{~Hz}), 4.90(\mathrm{~s}$, $4 \mathrm{H}), 2.96(\mathrm{dq}, 1 \mathrm{H}, \mathrm{J}=6.82 \mathrm{~Hz}), 0.90(\mathrm{~d}, 3 \mathrm{H}, \mathrm{J}=6.61 \mathrm{~Hz})$; high resolution MS (DCI with $\mathrm{NH}_{3}$ ) $\mathrm{m} / \mathrm{z} 168.1022$ $\left(\mathrm{C}_{9} \mathrm{H}_{14} \mathrm{NO}_{2}\left[\mathrm{M}+\mathrm{H}^{+}\right]\right.$requires 168.1024$)$.

(+)-(1S,2S)-1-(m-hydroxyphenyl)-2-amino-1-propanol (1d) The free base was converted to the fumarate salt and recrystallized from $\mathrm{CH}_{3} \mathrm{OH}$ :EtOAc (1:3) to give an analytical sample: $\mathrm{mp} 207-208^{\circ} \mathrm{C}$ (dec) (lit. ${ }^{13} 206-209^{\circ} \mathrm{C}$ ); $[\alpha]^{25}{ }_{\mathrm{D}}=+31^{\circ}\left(c=0.1, \mathrm{H}_{2} \mathrm{O}\right) \quad\left\{\right.$ lit. $^{13}[\alpha]^{25}{ }_{\mathrm{D}}=+26^{\circ}(c=2$, $\left.\left.\mathrm{H}_{2} \mathrm{O}\right)\right\}$. The ${ }^{1} \mathrm{H}$ NMR and mass spectral data corresponded with that reported for the $(1 \mathrm{R}, 2 \mathrm{R})$ isomer above.

\section{RESULTS AND DISCUSSION}

Prior approaches for preparation of the individual MHPA stereoisomers used either fractional recrystallization ${ }^{17,18}$ of the diastereomeric salts of tartaric acid (erythro series) or chemical methods ${ }^{13}$ (threo series). In our hands, these methods afforded both low product yields and optical purities (as determined by chiral HPLC analysis). The complexity of the previously described methods and the need for high optical purity prompted us to develop a chromatographic approach for the direct isolation of the individual MHPA stereoisomers.

Recent developments in chiral stationary phase (CSP) technology have allowed direct chromatographic resolution of a wide variety of racemic compounds without the need for prior derivatization. In particular, crown etherbased CSP systems (e.g., Crownpak $\mathrm{CR}^{\circledR}$ ), have demonstrated superior ability at chiral resolution of primary amine group-containing compounds such as amino acids and amino alcohols. ${ }^{19}$ Isomer separation in these chiral selectors is attributed to a preferential inclusion of the protonated amino group of one enantiomer in the crown ether (18-crown-6) pocket. ${ }^{19}$ Thus, enantiomers forming less stable complexes with the chiral crown ether elute prior to those forming more stable complexes. The presence of the amino alcohol functionality in MHPA led us to investigate its chromatographic behavior in this CSP system.
A mixture of all four MHPA stereoisomers was synthesized in $20 \%$ overall yield by a seven-step route ${ }^{15,16}$ using propiophenone as starting material. The presence of the $( \pm)$-erythro $(\mathbf{1 a}, \mathbf{1 b})$ and $( \pm)$-threo $(\mathbf{1 c}, \mathbf{1 d})$ enantiomeric pairs in the crude product was confirmed by their characteristic benzylic proton coupling constants of 5.6 and 7.5 $\mathrm{Hz}$, respectively, in the ${ }^{1} \mathrm{H}$ NMR spectrum. Integration of the benzylic proton peak areas showed a $3: 1$ concentration ratio for the (1a, 1b) and (1c, $\mathbf{1 d}$ ) enantiomeric pairs, respectively.

Analytical chiral HPLC analysis of the isomeric mixture was conducted using a Crownpak CR (+) chiral column as shown in Figure 2 (Mixture A). Elution of all four stereoisomers was complete within a 17 -min period after injection. The identity of each stereoisomer was confirmed by co-injection of the MHPA stereoisomeric mixture with the available analytical standards. Under these conditions, the $(-)$-enantiomers (1R configuration) elutes before the $(+)$ enantiomers (1S configuration) in the following increasing order of elution: (-)-threo (1c), (-)-erythro (1a), (+)-threo (1d), and (+)-erythro (1b), respectively. The chromatographic parameters obtained in this system are presented in Table 1. Baseline resolution was obtained for the $(+)$ stereoisomers (1b, 1d), whereas the (-)-stereoisomers (1a, 1c) were only partially resolved under these conditions. The relative HPLC peak areas of the erythro-to-threo diastereomeric products was approximately $3: 1$, in agreement with their concentration ratios obtained by ${ }^{1} \mathrm{H}$ NMR analysis.

Inspection of the elution profile of the MHPA stereoisomers suggested that the chromatographic resolution of the desired $\mathbf{1 b}, \mathbf{1 c}$, and $\mathbf{1 d}$ stereoisomers could be considerably improved by reducing the concentration of $\mathbf{1 a}$ in the mixture. This was accomplished by fractional crystallization of a major proportion of $\mathbf{1 a}$ from the initial mixture as its (+)-bitartarate salt. Thus, the isolation of two such crops of $\mathbf{1 a}$ crystals resulted in a 4 -fold decrease in its concentration in the mother liquors, as indicated by HPLC analysis (Fig. 2, Mixture B). In addition, improved resolution factors (Rs) of 1.58, 1.74 and 2.84 were obtained for the critical pairs (1a, 1c) (1d, 1a) and (1), 1d), respectively. The relative composition of each MHPA stereoisomer in the mixture before (Mixture A) and after selective removal of $\mathbf{1 a}$ (Mixture B) is shown in Table 2.

Preparative separation of a $120 \mathrm{mg}$ sample of Mixture B was carried out on a semipreparative Crownpak CR (+) column by repeated injections of $6 \mathrm{mg}$ portions of the mixture. UV absorbance was monitored at $290 \mathrm{~nm}$ to attenuate peak absorbance intensity. As the separation was conducted under column overload conditions, typically smaller 
TABLE 2. Relative composition (\%) of MHPA stereoisomers in Mixture A and Mixture B as determined by chiral HPLC analysis

\begin{tabular}{llrcc}
\hline Stereoisomer & $\mathbf{1 c}$ & $\mathbf{1 a}$ & $\mathbf{1 d}$ & $\mathbf{1 b}$ \\
\hline Mixture A & 11 & 38.5 & 12.4 & 38.1 \\
Mixture B & 15.9 & 8.7 & 18.2 & 57.2 \\
\hline
\end{tabular}

fractions $(1 \mathrm{ml})$ were collected during elution of the initial three components, followed by larger fractions $(2 \mathrm{ml})$ during elution of the more resolved final component, 1d. The optical purity of the fractions was confirmed by reinjection on the analytical system. Impure fractions were pooled, concentrated, and reinjected. Appropriate high purity fractions were combined and subjected to cation exchange chromatography to afford 1c (15 mg; 98\% ee), 1d (14 mg; $97 \%$ ee), and $\mathbf{1 b}$ (65 mg; 98\% ee), respectively, as the free base. Conversion to their respective bitartarate or fumarate salts and subsequent recrystallization provided optical purities $>99 \%$. The final products were fully characterized with respect to their physical (melting point, optical rotation) and spectral (NMR, mass spectra) properties.

It has been reported that decreasing the column operating temperature improves the separation factor $(\alpha)$ in these CSP systems..$^{19}$ Optimization of column temperature could therefore lead to further improvements in peak resolution and separation factors which would permit the injection of larger sample sizes. Furthermore, it may be possible to improve the purity of the individual fractions and also reduce the total number of fractions collected by inclusion of an in-line polarimeter in the system.

In conclusion, a sensitive chiral HPLC method for direct and rapid analysis of all four stereoisomers of MHPA is reported. This method is also sufficiently sensitive for the preparative isolation of milligram quantities of these isomers. Studies describing the carbon-11 labeling of these stereoisomers and their biological evaluation will be reported shortly.

\section{ACKNOWLEDGMENTS}

The encouragement and support of Dr. Donald M. Wieland during the course of this project is gratefully acknowledged. The author thanks Drs. Brian Tobias and Gary McClusky of Warner Lambert/Parke Davis, Ann Arbor, MI, for assistance in obtaining the optical rotations and the staff of the Phoenix Memorial Laboratory at the University of Michigan for the use of their facilities.

\section{LITERATURE CITED}

1. Ding YS, Fowler JS, Gatley SJ, Dewey SL, Wolf AP, Schlyer DJ. Synthesis of high specific activity 6 - $\left[{ }^{18} \mathrm{~F}\right]$ fluorodopamine for positron emission tomography studies of sympathetic nervous tissue. J Med Chem 1991;34:861-863.
2. Ding YS, Fowler JS, Gatley SJ, Dewey SL, Wolf AP. Synthesis of high specific activity $(+)$ - and $(-)-6-\left[{ }^{18} \mathrm{~F}\right]$ fluoronorepinephrine via the nucleophilic aromatic substitution reaction. J Med Chem 1991;34:767-771.

3. Goldstein DS, Eisenhofer G, Dunn BB, Armando I, Lenders J, Grossman E, Holmes C, Kirk KL, Bacharach S, Adams R, Herscovitch P, Kopin IJ. Positron emission tomographic imaging of cardiac sympathetic innervation using 6 - $\left[{ }^{18} \mathrm{~F}\right]$ fluorodopamine: initial findings in humans. J Am Coll Cardiol 1993;22:1961-1971.

4. Nagren K, Halldin C, Swahn C-G, Suhara T, Farde L. $\left[{ }^{11} \mathrm{C}\right]$ Metaraminol, a false neurotransmitter: preparation, metabolite studies and positron emission tomography examination in monkey. Nucl Med Biol 1996;23:221-227.

5. Chakraborty PK, Gildersleeve DL, Jewett DM, Toorongian SA, Kilbourn MR, Schwaiger M, Wieland DM. High yield synthesis of high specific activity R-(-)-[ $\left.{ }^{11} \mathrm{C}\right]$ epinephrine for routine PET studies in humans. Nucl Med Biol 1993;20:939-944.

6. Crout JR, Alpers HS, Tatum EL, Shore PA. Release of metaraminol (Aramine) from the heart by sympathetic nerve stimulation. Science 1964;145:828-829.

7. Giachetti A, Shore PA. Intracellular distribution of metaraminol and related compounds in rat heart. Life Sci 1965;4:1455-1460.

8. Rosenspire KC, Haka MS, Van Dort ME, Jewett DM, Gildersleeve DL, Schwaiger M, Wieland DM. Synthesis and preliminary evaluation of carbon-11-meta-hydroxyephedrine: a false transmitter agent for heart neuronal imaging. J Nucl Med 1990;31:1328-1334.

9. Allman KC, Stevens MJ, Wieland DM, Hutchins GD, Wolfe ER, Greene DA, Schwaiger M. Noninvasive assessment of cardiac diabetic neuropathy by carbon-11 hydroxyephedrine and positron emission tomography. J Am Coll Cardiol 1993;22:1425-1432.

10. Allman KC, Wieland DM, Muzik O, DeGrado TR, Wolfe ER, Schwaiger M. Carbon-11 hydroxyephedrine with positron emission tomography for serial assessment of cardiac adrenergic neuronal function after acute myocardial infarction in humans. J Am Coll Cardiol 1993;22:368375.

11. Schwaiger M, Hutchins GD, Kalff V, Rosenspire K, Haka MS, Mallette S, Deeb GM, Abrams GD, Wieland DM. Evidence for regional catecholamine uptake and storage sites in the transplanted human heart by positron emission tomography. J Clin Invest 1991;87:1681-1690.

12. Di Carli MF, Tobes MC, Mangner T, Levine AB, Muzik O, Chakraborty P, Levine TB. Effects of cardiac sympathetic innervation on coronary blood flow. N Engl J Med 1997;336:1208-1215.

13. Saari WS, Raab AW, Engelhardt EL. The stereoisomers of $\alpha$-(1aminoethyl)-m-hydroxybenzyl alcohol. J Med Chem 1968;11:11151117.

14. Snyder LR, Kirkland JJ. Introduction to modern liquid chromatography. New York: John Wiley \& Sons; 1979. p 22-37.

15. Bockmuhl M, Ehrhart G, Stein L. Process of preparing compounds of the 1-phenyl-2-aminoalcohols-1 series hydroxylated in the phenyl nucleus. U.S. Patent 1,948,162 (1934); Chem Abstr 1934;28:2849.

16. I. G. Farbenindustrie Aktiengesellschaft. Manufacture of 1-phenyl-2amino-alcohols-1 containing hydroxyl in the phenyl residue. Br. Patent 368,613 (1932); Chem Abstr 1933;27:2158.

17. I. G. Farbenindustrie Aktiengesellschaft. Manufacture of optically active 1-monohydroxy-phenyl-2-aminopropanols (1). Br. Patent 396,951 (1933); Chem Abstr 1934;28:482.

18. Albertson NF, McKay FC, Lape HE, Hoppe JO, Selberis WH, Arnold A. The optical isomers of metaraminol, synthesis and biological activity. J Med Chem 1970;13:132-134.

19. Shinbo T, Yamagushi T, Nishimura K, Sugiura M. Chromatographic separation of racemic amino acids by use of chiral crown ether-coated reversed-phase packings. J Chromatogr 1987;405:145-153. 